\title{
Impact of Personality Traits on Interpersonal Dependency
}

\author{
Dr. S. Jainab Zareena ${ }^{a, 1}$ Dr. M. Krithika ${ }^{b}$ \\ ${ }^{a}$ Assistant Professor, SCAD College of Engineering and Technology Tirunelveli, India \\ ${ }^{b}$ Assistant Professor, Saveetha School of Engineering, Chennai, India
}

\begin{abstract}
Every person has a unique personality. A set of characteristics or qualities possessed by an individual is called as the personality traits. Interpersonal dependency refers to the amount of support that an individual gets from the other person and the level of it gets varied among the people. Those who have higher interpersonal dependency are labeled as low self- esteemed person. The present study is initiated to identify the traits possessed by an interpersonal dependent. An adapted questionnaire is used for the study. Totally the questionnaire consists of seventeen questions among which ten questions measured the variable personality traits and the remaining seven questions measured the variable interpersonal dependence. The data was collected from fifty employees working in corporate for the present study. Content and face validities are used to assess the validity. Inferences are drawn through the use of descriptive and inferential statistic.
\end{abstract}

Keywords: Personality traits, interpersonal dependency, self-esteem, negative traits.

\section{Introduction}

Personality traits are the characteristics or qualities that an individual possess. We all have remarkable personality that makes us unique as compared to the others. Through earlier research studies it is evident that every individual acquire more traits between childhood to adolescence stage and specifically maturity is observed in adulthood stage (Roberts et al. 2006). Personality is structured or built based on five traits namely (i) openness - open minded and challenging person, (ii) conscientiousness - selfdisciplined, (iii) extraversion- interpersonal relationship that one has with the another, (iv) agreeableness - tactful and friendly person, and neuroticism-stable and balanced persons. Previous studies Previous studies highlighted the fact that the level of neuroticism decreases when the level of agreeableness and conscientiousness increases (Kotov et al. 2010). Career is established at the earlier stages of life. During high school, ambitious children will put more effort in their studies. Some roles are forced upon by the society in our late adolescence and young adulthood stage. For example a newly married man may be advised by his elders to be responsible towards his wife or a youth may be advised by his parents to save the money which he earns

\footnotetext{
${ }^{1}$ Dr. S. Jainab Zareena ,Assistant Professor SCAD College of Engineering and Technology Tirunelveli. Email:
} 
(Lodi-Smith et al.2007). Being engaged in an intimate relationship is one of the social roles and is performed based on the two criteria. First is one should find a perfect person to develop intimacy and the second is an individual's desire to maintain relationship with one person. Some of the research studies concluded that intimate relationships are captured through identity process (Marcia, 1966). A study conducted by Engel et al. 2002 revealed a strong positive correlation between the personality traits, conscientiousness and interpersonal commitment. Another trait that correlates positively with interpersonal commitment is agreeableness. One's willingness to proceed with a relationship positively influenced interpersonal identity in many studies. Therefore, a strong interpersonal identity has a lower probability of experiencing breakup.

Markus Jokela, (2011) carried out research to investigate the relationship between socioeconomic status and depressive symptoms. The study had two thousand six hundred and seventy eight respondents falling in between the age group of eighteen to forty nine. The socio economic status is assessed by three attributes namely education, occupational status and income level. The study revealed the strong association between low occupational status/ income and depression. It was also found that many individuals suffered from mental health problems due to high depression. Specifically, high level depression was found in individuals with high neuroticism and low extraversion trait. Further, Albrecht et al. (2013) conducted study to assess personality characteristics and academic performance of medical students. Seven hundred and eighty five medical students were the respondents of the study. The result revealed that majority of the students fall under the category of extraversion and agreeableness. Students with low conscientiousness and high sociability were found less likely to sit examination successfully. Similar studies conducted in this area of research proved significant relationship between personality traits and behaviour (Hare and Neumann, 2008; Krueger and Markon,2014; Tyrer, 2015; Lampe and Malhi, 2018). The present study is initiated to identify the traits possessed by an interpersonal dependent. The conceptual frame work of the study is given in fig 1 .

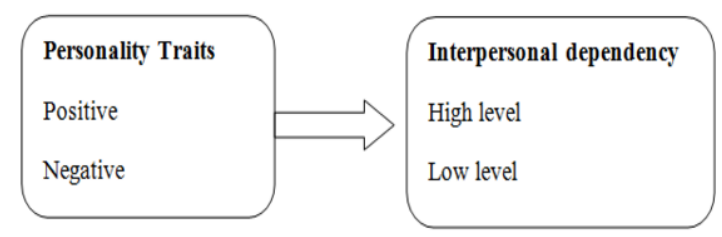

Figure 1.Framework of the Study

\section{Methodology\&Analysis}

An adapted questionnaire is used for the study. Totally the questionnaire consists of seventeen questions among which ten questions measured the variable personality traits and the remaining seven questions measured the variable interpersonal dependence. The data was collected from fifty respondents working in multinational organizations. The convenient sampling technique was used. Content validity is established by 
considering the recommendations of professionals working in different organizations. Face validity is established by seeking the opinion of respondents about the questionnaire. Inferences are drawn through the use of descriptive and inferential statistic. The demographic details of the sample are tabulated in table 1.

Table 1.Demographic details of the sample

\begin{tabular}{cllc}
\hline S. No & Variables & Category & $\begin{array}{c}\text { Number } \\
\text { (out of 50) }\end{array}$ \\
\hline 1 & Gender & Male & 30 \\
$\cdot$ & & Female & 20 \\
& & IT & 35 \\
& & & \\
2. & Industry type & Non IT & 15 \\
& & 3 years and below & 6 \\
3 & Working experience & $4-7$ years & 7 \\
& & 8 years and above & 2 \\
4 & Educational Qualification & Post Graduation & 25 \\
& & Under Graduation & 25 \\
\hline
\end{tabular}

Pearson Correlation Analysis is calculated to study the relationship amongst the variables. A strong positive correlation is found to exist between the negative traits and high level interpersonal dependency. Based on the findings it is inferred that the people with interpersonal dependency possess negative personalitytraits. Note: ${ }^{*} \mathrm{p}<.01,{ }^{*} \mathrm{p}<$ $.05, \mathrm{~ns}=$ not significant Multiple Regression Analysis is calculated to identify which one of the independent variable (positive traits - positive, negative) highly influence the dependent variable (interpersonal dependency). The results are tabulated in table 3. Based on the findings it is inferred that the negative personality trait highly influences the dependent variable interpersonal dependency.

Table 2. Pearson Correlation coefficients

\begin{tabular}{|l|l|l|}
\hline Variables & Beta & p value \\
\hline Positive personality trait & 0.453 & $0.083(\mathrm{~ns})$ \\
\hline Negative personality trait & 0.653 & $0.016^{*}$ \\
\hline
\end{tabular}


Table 3.Multiple Regression - Beta and p value

\begin{tabular}{|l|l|l|l|l|}
\cline { 2 - 5 } \multicolumn{1}{l|}{} & \multicolumn{2}{|l|}{$\begin{array}{l}\text { Interpersonal dependency } \\
\text { High level }\end{array}$} & \multicolumn{2}{l|}{$\begin{array}{l}\text { Low level } \\
\text { Low lenal dependency }\end{array}$} \\
\hline $\begin{array}{l}\text { Variables } \\
\text { Porsonality Traits }\end{array}$ & r value & p value & r value & p value \\
\hline & 0.283 & $0.621(\mathrm{~ns})$ & 0.111 & $0.101(\mathrm{~ns})$ \\
\hline Negative & & $0.000^{* *}$ & 0.243 & $0.081(\mathrm{~ns})$ \\
\hline
\end{tabular}

Note: ${ }^{* *} \mathrm{p}<.01,{ }^{*} \mathrm{p}<.05, \mathrm{~ns}=$ not significant

Dependent Variable: Interpersonal dependencyFemale respondents obtained higher mean scores $($ mean $=6.51)$ than the male respondents $($ mean $=4.32)$. Based on the findings it is inferred that the women respondents have higher interpersonal dependency as compared to the male respondents

\section{Conclusion}

Openness has been associated with learning styles that often lead to academic success and higher grades such as analysis of synthesis and methodological study. Conscientiousness and openness are found to predict all four learning styles. Individuals with personality traits such as discipline, commitment, and curiosity are more likely to participate in any one of the learning styles. The most critical thing to remember about interpersonal dependency is self-confidence. One should be selfconfident. The study undoubtedly proves the fact that an interpersonal dependent will possess negative traits. However, one can overcome interpersonal dependency. The present study recommends 'can-do attitude' for those who always rely on others.

\section{References}

[1] Roberts, Brent W., Kate E. Walton, and Wolfgang Viechtbauer. Patterns of mean-level change in personality traits across the life course: a meta-analysis of longitudinal studies.Psychological bulletin 132.1 (2006): 1.

[2] Kotov, Gamez, Schmidt, \& Watson. Linking big personality traits to anxiety, depressive, and substance use disorders: a meta-analysis. Psychological bulletin 136.5 (2010):768

[3] Marcia, James E. Development and validation of ego-identity status.Journalof personality and social psychology 3.5 (1966):551.

[4] Engel, Gina, Kenneth R. Olson, and Carol Patrick. The personality of love:Fundamental motives and traits related to components of love. Personality and Individual Differences32.5 (2002):839-853.

[5] Huitt, William G. Personality Differences Between Navajo and Non-IndianCollege Students: Implications for Instruction. Equity \& Excellence 24.1 (1988):71-74. 
[6] Albrecht AG, Paulus FM, Dilchert S, DellerJ, Ones DS. Construct-and criterion-related validity of the German Core Self-Evaluations Scale. Journal of Personnel Psychology. 2013 May6.

[7] Lounsbury, Sundstorm, Loveland and Gibson. Broad versus narrow personality traits in predicting academic performance of adolescents. Learning and individual differences 14.1 (2002):65-75.

[8] Hare, R. D., \& Neumann, C. S. (2008). Psychopathy as a clinical and empirical construct. Annu. Rev. Clin. Psychol., 4,217-246.

[9] Krueger, R. F., \&Markon, K. E. (2014). The role of the DSM-5 personality trait model in moving toward a quantitative and empirically based approach to classifying personality and psychopathology. Annual review of clinical psychology, 10,477-501.

[10] Tyrer, P., Reed, G. M., \& Crawford, M. J. (2015). Classification, assessment, prevalence, and effect of personality disorder. The Lancet, 385(9969),717-726.

[11] Lampe, L., \&Malhi, G. S. (2018). Avoidant personality disorder: current insights. Psychology research and behaviormanagement.

[12] Lodi-Smith, Jennifer, and Brent W. Roberts. Social investment and personality: A meta- analysis of the relationship of personality traits to investment in work, family, religion, and volunteerism. Personality and social psychology review 11.1 (2007):68-86.

[13] AnkitKumar,VijayakumarVaradarajan,AbhishekKumar, PankajDadheech, SurendraSinghChoudhary, V.D. AmbethKumar, B.K.Panigrahi, KalyanaC.Veluvolug.Black hole attack detection in vehicular adhoc network using secure AODV routing algorithm.Microprocessors and Microsystems, In Press,(https://doi.org/10.1016/j.micpro.2020.103352)

[14] VDAK, A Cognitive Model for Adopting ITIL Framework to Improve IT Services in Indian IT Industries. Journal of Intelligent Fuzzy Systems. (DOI: 10.3233/JIFS-189131 )(Accepted - Inpress)

[15] V.D.Ambeth Kumar. Efficient Data Transfer in Edge Envisioned Environment using Artificial Intelligence based Edge Node Algorithm.Transactions on Emerging Telecommunications Technologies (Accepted - Inpress)(DOI: 10.1002/ett.4110)

[16] E.Dhanabal, G.Harish, S.YogaDinesh, V.D.Ambethkumar, M. Rajendiran. Cryptographic enhanced shared data on conserve encipher text update in cloud computing.Advances in Natural and Applied Sciences, 11(6), 2017

[17] A.Santhiya, K.Valarmathi .Android Based Women Tracking System Using GPS and GSM. International Journal for Research in Applied Science \& Engineering Technology, 4(4),pp181-186, 2017

[18] Vimala.S, Thilagavathi.S, K.Valarmathi, R.Priya, S.Sathya .Massive Data Processing Using Map Reduce Aggregation to make Digitized India.Advances in Engineering Research, vol. 142, Pp.88-92, 2019

[19] K. Nanagasabapathy; G. Harish; O. I. Allen Sebastian; N. Sowrabh Chandra; V. D. Ambeth Kumar," Validation system using smartphone luminescence", IEEE International Conference on Intelligent Computing, Instrumentation and Control Technologies (ICICICT), Pages: 235 - 239, 6-7 July 2017, Kannur, India

[20] V. D. Ambeth Kumaret.al , “ Cloud enabled media streaming using Amazon Web Services”, IEEE International Conference on Smart Technologies and Management for Computing, Communication, Controls, Energy and Materials, Pages: 195-198, 2-4 Aug. 2017, India (DOI: 10.1109/icstm.2017.8089150)

[21] B. Aravindh; V.D.Ambeth Kumar; G. Harish; V. Siddartth, “ A novel graphical authentication system for secure banking systems", IEEE International Conference on Smart Technologies and Management for Computing, Communication, Controls, Energy and Materials (ICSTM), Pages: 177 - 183, 2-4 Aug. 2017, DOI: 10.1109/ICSTM.2017.8089147 